\title{
¿QUÉ ESPERAMOS LOS MAPUCHES DE LA IGLESIA?
}

\author{
Domingo Nahuelcura ${ }^{1}$
}

\section{Desde el Sufrimiento del pueblo mapuche...}

Quiero comenzar este testimonio con algunas reflexiones que a lo largo de mi vida he ido recogiendo ya desde mi propia vivencia de mapuche como del testimonio de muchos otros hermanos.

No hay peor drama para un hombre y una mujer que el no sentirse querido y aceptado. En efecto, quien no se siente amado y acogido corre el riesgo de perder su razón de ser, su autoestima y hasta su dignidad de persona. A través de los años generaciones de mapuches han vivido la experiencia del rechazo y la marginación. En esta sociedad racista y clasista marcada por la economía liberal, ser moreno es difícil y ser moreno y mapuche lo es aun más. Ser mapuche en Temuco, en Chile y en nuestra Iglesia es un desafío que nos marca profundamente.

No planteo esto desde un resentimiento antojadizo, sino desde la perspectiva de quien ha tenido que superar muchas barreras que se nos imponen sólo por nuestro origen indigena. Estas barreras, que no tienen que ver sólo con un problema particular de imagen, nos acompañan durante largos períodos de nuestra vida y dejan en nosotros profundas heridas. Somos un pueblo marcadamente diferente, y vivir esta diferencia es un desafío del cual no siempre se sale incólume.

Por todo esto, creo que es fundamental decir lo que muchos de mis hermanos plantean hoy con mucha fuerza sobre las verdades históricas, sobre la verdad oficial tan contrapuesta a la historia sentida y vivida por nuestro pueblo. Fundamentalmente, desenmascarar al Estado chileno, que con sus instituciones nos quitó, nos robó y se apropio de las tierras mapuches, al margen de toda legislación nacional e internacional. El proceso de apropiación ilegitima que se vivió principalmente durante la segunda mitad del siglo XIX, y que se pretende suavizar llamándolo eufemísticamente "pacificación", significó un verdadero genocidio y etnocidio para nuestro pueblo. Yo me pregunto, ¿cuanto dolor? ¿cuantos sueños se quebraron en este proceso? Cuando era niño mi abuela me contaba historias que no me parecian reales, con el paso del tiempo me di cuenta que si lo eran y me comprometí con el sufrimiento de ese pueblo que clama hasta Dios su liberación.

Desde la conquista hasta el día de hoy nuestro pueblo ha debido sufrir el saqueo de las riquezas naturales presentes en su territorio -hoy mayoritariamente 
enajenado- primero por conquistadores y encomenderos, y luego por empresas nacionales y transnacionales que se amparan en el aparato estatal. Pero lo más grave ha sido el secuestro de nuestra identidad y de nuestra memoria como pueblo. Se nos mutiló. Se mutiló nuestra sabiduria, nuestra ciencia, nuestra religión, nuestras instituciones tradicionales de organización, el sentido comunitario de la vida, nuestra relación con la madre tierra, etc. Mutilación y despojo en que tuvieron responsabilidad y participación muchos cristianos.

\section{... QUÉ LE PEDIMOS LOS MAPUCHES A LA IGLESIA?}

Después de situarnos en el contexto apropiado quiero expresar aquello que los mapuches pedimos a la Iglesia. Lo hago desde mi perspectiva personal marcada por mi experiencia de trabajo durante años en comunidades campesinas mapuches, lugar en el que he sido testigo de la memoria histórica y social de mi pueblo transmitida por generaciones a través de su oralidad y su vivencia comunitaria. Puedo afirmar con propiedad que conozco sus dolores y sus esperanzas; y, por lo mismo, puedo reconocer y decir con una voz fuerte y clara, que la Iglesia de Temuco ha hecho grandes esfuerzos y ha alcanzado grandes metas en el plano de la evangelización y de la acción social en bien de nuestras comunidades. Organismos como la Fundación Instituto Indigena o el equipo de Pastoral Mapuche a través de las parroquias, han sido espacios en donde presbíteros, laicos y religiosas guiados por el pastor diocesano, Don Sergio Contreras, han hecho suyo el compromiso con este pueblo sufrido y postergado.

Sin embargo, y a pesar de grandes esfuerzos, los mapuches nos sentimos postergados pues no vemos una voluntad general de parte del resto de la lglesia por avanzar hacia una Iglesia de rostro verdaderamente mapuche. Desde hace mucho tiempo los mapuches hemos hecho planteamientos sobre esto de diferentes maneras y con mucha fuerza, pero no hemos sido escuchados. Pedimos en primer lugar que se rescate nuestra historia, con todo lo que ella significa; en segundo lugar, y sobre todo en este año del Jubileo, un esfuerzo mayor por la restitución de la tierra, por la restauración de nuestro tejido social respetando nuestras autoridades tradicionales. Aquí, sería bueno que la Iglesia reconociera explícitamente que cometió errores históricos que dañaron la vida de nuestra gente y que hiciera gestos de arrepentimiento y reparación. Que en esta misma línea, alce con mayor fuerza su voz profética en defensa de los derechos de nuestro pueblo. Le pedimos que nos deje ser protagonistas de nuestra historia personal y colectiva, pues no necesitamos paternalismos asistencialistas, ni queremos que nos traten como ciudadanos de segunda clase o laicos de segunda categoría.

Pedimos, en tercer lugar, rescatar y valorizar nuestra sabiduría que está presente en el imaginario de nuestro pueblo, en su lengua, en sus dichos, en los mitos fundadores que recibimos de nuestros ancestros, en nuestros ritos y fiestas, en las costumbres familiares, en el trabajo comunitarios, etc. Aqui se hace urgente realizar un diálogo profundo, teológico y pastoral, de aprendizaje mutuo y de reciproca evangelización.

Pedimos, por ejemplo, que en las celebraciones litúrgicas los presbíteros conozcan y admitan nuestra lengua materna en la oración y nos dejen celebrar con 
nuestra música y nuestros instrumentos. Que la expresión cultual católica deje de ser tan winca y se haga más nuestra.

Yo creo que el Dios de la vida y de la misericordia no llegó aquí con los conquistadores y misioneros, él ya estaba presente en medio de nuestro pueblo mapuche, y en todas las culturas originarias del continente. Porque la revelación no se restringe solamente a la experiencia judeo-cristiana de Dios; puesto que Dios visitó a su pueblo y a sus pueblos desde siempre. Esto es lo que pienso y lo que creo.

Nosotros, los mapuches, hemos demostrado en la historia que somos capaces de resistir y levantarnos a pesar de las adversidades, la miseria y el abandono, pues somos un pueblo vivo y en marcha, un pueblo tenaz y dinámico que nunca ha estado muerto ni vencido, como muchos pretenden. Hoy nos sentimos llamados por el señor de la historia a un encuentro con nosotros mismos, con nuestras raices, con nuestra historia y nuestra cultura. Los mapuches cristianos católicos estamos dispuestos a caminar en esta propuesta junto a nuestro pueblo, a nuestra Iglesia y toda la sociedad chilena, y pedimos fervientemente al Espíritu Santo que nos ayude en esta tarea, para que nuestra pueblo camine con todos los pueblos por la experiencia nueva del reino, y no nos sintamos extranjeros en nuestra propia tierra. 